\title{
Focus and Perspectivism in Viewing Information and Informing
}

\section{Zbigniew J. Gackowski \\ California State University Stanislaus, Turlock, CA, USA}

\section{ZGackowski@csustan.edu}

\begin{abstract}
In the theory of knowledge, Nietzsche articulated the principle of perspectivism. Using a simplified example, this paper illustrates how changing the optical perspective dramatically changes the results of observations. In the age of information, we still are far away from a reasonable consensus in viewing information and informing. Callaos and Callaos (2002) tried to integrate the disparate views (without excluding any of them) into a systemic notion of information based on distributive notion of truth. Alas, this attempt did not bring us closer to a cohesive view for research and practice. Misplaced focus and ignored perspective seem to be the root cause of lack of success. By placing the disparate views found in scholarly literature into a down-to-earth context of routine human-controlled operations and processes observed in nature most of them can be clarified, explained, dispelled, or refuted.
\end{abstract}

Keywords: Perspectivism, focus, information, informing, disparate views, lack of consensus

[Full paper to be published in Informing Science: the International Journal of an Emerging Transdiscipline.] 